\title{
A informação como um elemento chave para a qualidade do produto turístico: uma análise dos postos de informações turísticas do município de Florianópolis/SC
}

Cláudia Fabiana Gohr

Doutora em Engenharia de Produção pela Universidade Federal de Santa Catarina (UFSC) Professora da Faculdade de Administração, Ciências Contábeis e Economia da Universidade Federal da Grande Dourados (UFGD).

Luciano Costa Santos

Doutor em Engenharia de Produção pela Universidade Federal de Santa Catarina (UFSC). Professor da Faculdade de Ciências Exatas e Tecnologia da Universidade Federal da Grande Dourados (UFGD).

Mariana Feminella Veiga

Graduada em Turismo e estudante do curso de Administração. Funcionária da Universidade Federal de Santa Catarina.

Os Postos de Informações Turísticas de uma localidade são unidades de informação fundamentais para a cadeia do turismo. Este artigo apresenta um estudo exploratório que teve o objetivo de analisar as condições dos Postos de Informações Turísticas (PIT's) do município de Florianópolis/SC para garantir a qualidade do atendimento aos turistas. Após uma análise crítica dos PIT's do município, foram propostas algumas sugestões de melhoria que podem contribuir para a operacionalização dos objetivos estabelecidos pelas políticas públicas de informação ao turista.

Palavras-chave: Informação; Turismo; Qualidade; Postos de Informações Turísticas. 


\title{
Information as a key element to the quality of tourism product: an analysis of tourism information centers at Florianópolis/Brazil
}

\begin{abstract}
Tourism Information Centers are important information units for the tourism chain. This paper presents an exploratory study which aimed at examining the Tourism Information Centers (TICS) of Florianópolis/Brazil in their ability to assure service quality for the visitors. After a critical analysis of the TICs, some suggestions of improvement were proposed that might contribute for implementation of the goals set by public policies for tourism information.
\end{abstract}

Keywords: Information; Tourism; Quality; Tourism Information Centers.

Recebido em 23.03.2009 Aceito em 24.07.2009

\section{Introdução}

Nos dias atuais, é possível verificar que a gestão da informação tem recebido uma forte atenção no setor de turismo. O interesse é justificável, pois tem sido notória a constatação de que a informação é o ponto de partida para o turista no processo de decisão por um destino, e representa um dos componentes fundamentais do produto turístico.

A vasta literatura sobre gestão da informação tem influenciado no aumento de pesquisas sobre a busca e a utilização de informações pelos turistas, o que tem resultado em diversos trabalhos publicados recentemente na área de Turismo (SEABRA; ABRANTES; LAGES, 2007; NISHIMURA; WARYSZAK; KING, 2006; LEHTO; KIM; MORRISON, 2006). No entanto, na maioria das vezes esses trabalhos estão relacionados com a busca de informações que ocorre no período que antecede a viagem (NISHIMURA; WARYSZAK; KING, 2006). Na prática, os turistas fazem escolhas e tomam decisões tanto antes quanto durante a realização da viagem, especialmente os turistas que viajam de forma independente.

As informações coletadas pelos turistas antes da viagem geralmente são aquelas relacionadas à escolha do destino, enquanto as informações coletadas pelos turistas durante a viagem se referem às atividades que serão desenvolvidas no destino selecionado. Tais atividades correspondem aos potenciais atrativos da região, à hospedagem, à alimentação, ao transporte local, às vias de acesso, dentre outros. 
Nascimento e Silva (2004) categorizam as informações geradas pelo e para o turismo em três tipos básicos: informação para gestão empresarial (subsidia o desenvolvimento das atividades das empresas ligadas ao turismo), informação para divulgação do turismo e informação para o turista (satisfaz as necessidades de informação do turista durante a sua estadia no destino). Utilizando essa classificação, o foco desse artigo está na última categoria, isto é, naquelas informações de que o usuário necessita durante a realização da viagem, em particular as informações fornecidas pelos Postos de Informações Turísticas (PIT's).

O conjunto dos Postos de Informações Turísticas de uma localidade representa um dos elementos básicos do produto turístico (AUGUSTYN, 1998) e tem como principal finalidade atender, de modo eficiente, o visitante durante o período de permanência no destino (DE LUCCA FILHO, 2005). A busca crescente por viagens independentes torna os serviços de informações turísticas importantes elos de segurança do visitante com o destino. Assim, a responsabilidade dos PIT's em oferecer informações confiáveis e de forma adequada é reforçada por sua contribuição essencial para a qualidade do produto turístico.

A avaliação da qualidade do produto turístico não é uma tarefa simples, pois o produto turístico é complexo e multidimensional. A análise dos Postos de Informações Turísticas de uma localidade ou região procura dar suporte para a avaliação de uma das dimensões essenciais do produto turístico total. Nesse sentido, este artigo se propõe a responder à seguinte pergunta de pesquisa: Quais são as condições dos PIT's do município de Florianópolis/SC para garantir a qualidade do atendimento aos turistas?

Pelo fato de os PIT's serem considerados prestadores de serviços de informação, foi utilizado o arcabouço teórico sobre qualidade em serviços como referencial de análise. Assim, pode-se afirmar que o foco deste trabalho não está no conteúdo da informação, mas sim no processo, ou seja, na maneira pela qual a informação é transmitida e disseminada. Por se tratar de um estudo inicial, de caráter exploratório, os PIT's foram analisados apenas do ponto de vista dos atendentes e dos pesquisadores, de forma a apoiar futuras pesquisas que incluam estudos de usuários da informação e permitam ampliar o grau de generalização das conclusões obtidas.

A estrutura do texto apresentado inclui uma revisão de literatura sobre a importância da informação para a atividade turística e sobre o papel dos PIT's na garantia de qualidade do produto turístico. Posteriormente, são descritos os procedimentos metodológicos que definem os parâmetros da pesquisa e os aspectos adotados para analisar as condições de atendimento ao turista nos PIT's do município de Florianópolis/SC. Ao final, são apresentados os resultados da análise e as principais conclusões acerca do trabalho realizado. 


\section{A importância da informação no turismo}

Para entender a importância da informação no turismo, é necessário definir um conceito-chave nos estudos de Turismo: o produto turístico. 0 produto turístico pode ser considerado como o conjunto de bens e serviços consumido pelos visitantes em um determinado destino (COOPER et al., 2001). Segundo Middleton (2002, p. 135),

o produto [turístico] pode ser definido como um pacote de componentes tangíveis ou não, com base na atividade de um destino. O pacote é percebido pelo turista como uma experiência disponível a um determinado preço.

De acordo com Wheeler (1995), a principal característica do produto turístico é a experiência do lugar (localidade e pessoas) durante um determinado período de tempo. Além disso, como a cadeia do turismo é formada basicamente por prestadores de serviços, o produto turístico possui as características inerentes aos serviços que são freqüentemente destacadas na literatura: a intangibilidade, a perecibilidade, a inseparabilidade entre produção e consumo e a heterogeneidade de resultados (MIDDLETON, 2002; COOPER et al., 2001; RUSCHMANN, 1999; HU, 1996; ZEITHAML; PARASURAMAN; BERRY, 1985). De acordo com Seabra, Abrantes e Lages (2007) e Wheeler (1995), o produto turístico ainda apresenta uma complexidade adicional, pois necessita de vários componentes complementares provenientes de diferentes agentes, sejam eles públicos, privados ou voluntários, conforme pode ser observado na FIG. 1, ilustrada a seguir.

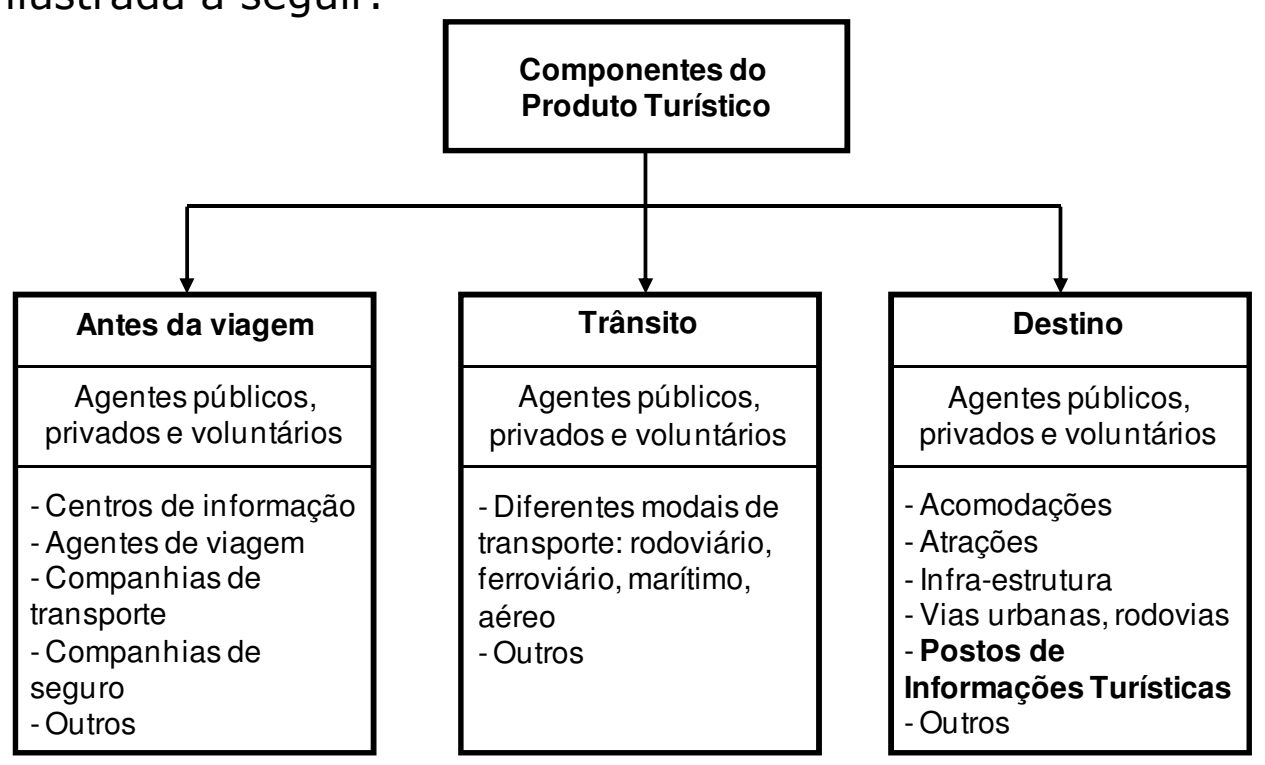

FIGURA 1 - Componentes do produto turístico

Fonte: Adaptado de AUGUSTYN (1998). 
Na FIG. 1 é possível verificar que a informação é um dos componentes centrais do produto turístico. Hu (1996) afirma que as informações representam o conteúdo do processo de comunicação entre o destino e o turista, sendo consideradas importantes e críticas para a retenção dos turistas em um determinado destino. A comunicação entre destino e turista ocorre em diferentes momentos: antes da viagem (proveniente principalmente de fontes externas à localidade), no trânsito e durante a estadia no destino (SEABRA; ABRANTES; LAGES, 2007; NISHIMURA; WARYSZAK; KING, 2006; AUGUSTYN, 1998; HU, 1996).

No período que antecede a viagem, a informação pode interferir significativamente na motivação do viajante para conhecer determinado destino. A figura 2 ilustra o processo de informação mediante o qual são criadas as imagens e os conceitos sobre um destino turístico.

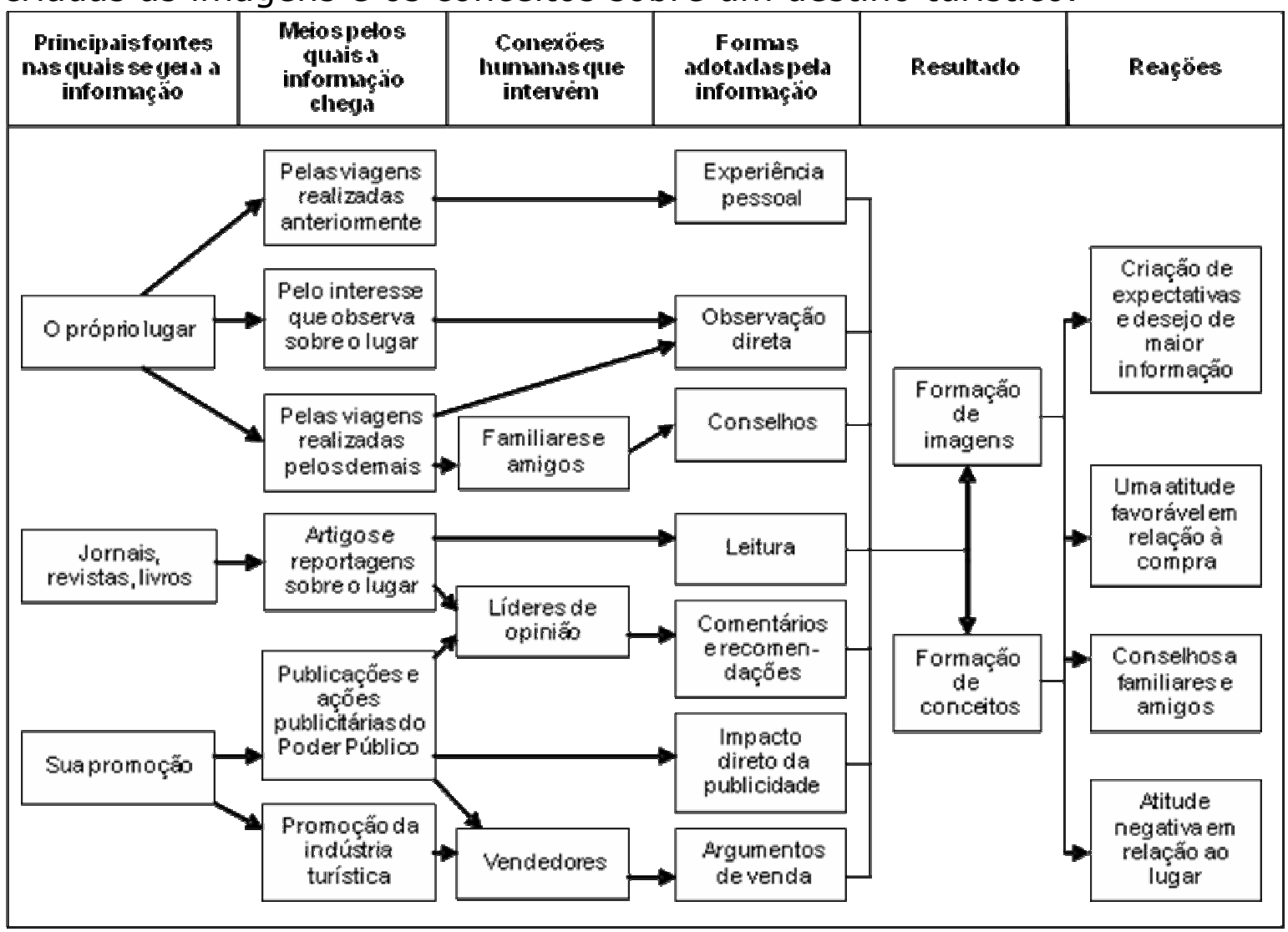

FIGURA 2 - Processo de informação sobre um destino turístico

Fonte: ACERENZA (2002, p. 207).

Todos os agentes do turismo (órgãos e entidades governamentais, fornecedores, operadoras, agências de viagens e turistas) interagem na cadeia turística com informações necessárias para a dinâmica da atividade. Nessa cadeia é possível estabelecer uma íntima relação entre o turismo e a necessidade de informações para seus usuários. Vários autores abordam esse relacionamento, conforme pode ser observado no QUADRO 1. 
QUADRO 1 Relação da atividade turística com a informação

\begin{tabular}{c|l}
\hline Autor(es) & \multicolumn{3}{|c}{ Relação do turismo com a informação } \\
\hline \hline & $\begin{array}{l}\text { Na rotina da atividade turística existe a geração, a coleta, o } \\
\text { processamento, a aplicação e a comunicação da informação. A } \\
\text { informação é o laço que amarra todos os componentes da indústria } \\
\text { turística. }\end{array}$ \\
\hline $\begin{array}{c}\text { Naisbitt } \\
(1994)\end{array}$ & $\begin{array}{l}\text { Com o crescimento do turismo e com a sofisticação dos viajantes, a } \\
\text { demanda por informações levará a uma interconectividade ainda maior. }\end{array}$ \\
\hline $\begin{array}{c}\text { Buhalis } \\
(1998)\end{array}$ & Informação é vital para a indústria de viagens. \\
\hline $\begin{array}{c}\text { Cooper et al. } \\
(2001)\end{array}$ & $\begin{array}{l}\text { A atividade turística depende da boa disseminação de informações e da } \\
\text { distribuição eficaz do produto turístico. }\end{array}$ \\
\hline $\begin{array}{c}\text { O'Connor } \\
(2001)\end{array}$ & $\begin{array}{l}\text { O turismo depende cada vez mais da informação. A informação é o } \\
\text { nutriente básico do turismo. }\end{array}$ \\
\hline $\begin{array}{c}\text { Middleton } \\
(2002)\end{array}$ & $\begin{array}{l}\text { O turismo é um mercado totalmente baseado no fornecimento de } \\
\text { informações. }\end{array}$ \\
\hline Fon
\end{tabular}

Fonte: Adaptado de DE LUCCA FILHO (2005).

Levando em consideração a relevância da informação para o turismo, pode-se ressaltar que os Postos de Informações Turísticas (PIT's) influenciam diretamente na qualidade do produto turístico. Isso ocorre principalmente em função de turistas mais viajados, mais experientes e mais exigentes, que passam a ter necessidades específicas de informação (NASCIMENTO; SILVA, 2004). Os PIT's constituem-se em um dos elementos responsáveis para a formação do produto turístico, portanto, são também responsáveis pela permanência e pelo retorno do turista. Nesse contexto, verificar se os PIT's estão preparados para receber os turistas torna-se uma questão relevante para a construção de um turismo de qualidade.

\section{0 papel dos postos de informações turísticas}

Quando os turistas chegam aos destinos, eles são atendidos pelos responsáveis do turismo receptivo, definido por Teixeira (1999) como o conjunto de atividades responsáveis pela acolhida dos viajantes nos locais, desenvolvidas pelo setor público e pelo setor privado. Ao setor privado competem as atividades empresariais, enquanto ao setor público cabe a manutenção da infra-estrutura para o desenvolvimento turístico, gerenciando atividades como: segurança, abastecimento de água, limpeza urbana, sinalização viária e informações turísticas. Os PIT's são de responsabilidade do setor público e se inserem no sistema turístico como parte da infra-estrutura de que uma localidade necessita para atender ao turista (BENI, 2003).

Os PIT's são considerados essenciais para o desenvolvimento da atividade turística, pois são os responsáveis pelas informações que orientam os turistas em uma localidade. As funções dos PIT's, segundo De Lucca Filho (2005), são: fornecer informações turísticas; prestar serviços de agências de viagens (reservas de serviços em estabelecimentos 
turísticos - meios de hospedagem, traslados, serviços de guias de turismo, reservas em shows e outros eventos, dicas de atrativos turísticos); disponibilizar banheiros; e disponibilizar serviços de alimentação (restaurantes, lanchonetes e lojas de conveniência).

Além disso, de acordo com De Lucca Filho (2005), os PIT's podem manter um banco de dados de visitantes, sendo que essas informações podem facilitar as ações de promoção e fidelização dos turistas. Segundo o autor, um PIT deve conter vestiários, sanitários, salas, balcões, serviços de informática, setor de escritórios para as atividades administrativas e informativas (equipado com telefone, fax, telex, sistemas de informação, videotexto, etc.), arquivo de material de propaganda e arquivo geral com banco e base de dados informatizados.

Silva (2000) também afirma que os PIT's podem coordenar os dados estatísticos da atividade turística, auxiliando na sistematização e adequação do volume de informações para suprir o sistema turístico de informações confiáveis, subsidiando as decisões relativas aos investimentos públicos e privados, por meio do acompanhamento das relações de mercado e das projeções de longo prazo. Os dados estatísticos servem para direcionar os investimentos públicos em áreas prioritárias, para conhecer melhor o turista e para adequar as informações turísticas necessárias aos visitantes. Dessa forma, os PIT's podem auxiliar nas políticas públicas do turismo, desde que estejam operando em consonância com as mesmas.

De acordo com De Lucca Filho (2005), as informações turísticas mais procuradas nos PIT's são sobre: meios de hospedagem, atrativos naturais, atrativos histórico-culturais, equipamentos de alimentação, equipamentos de lazer e entretenimento. Montejano (2001) afirma que os PIT's devem se basear em informações de empresas, instituições, organizações turísticas e recursos turísticos. Além disso, os PIT's devem desenvolver processos para adquirir informações relacionadas aos turistas, analisar a informação, catalogar e arquivar as informações (manual ou de forma informatizada), atualizar a informação e ter sistemas integrados de reserva.

Devido à complexidade das atividades dos PIT's e à sua importância para o turismo, o tipo de informação e a forma como ela é fornecida influenciam na qualidade percebida dos diferentes destinos turísticos. Atualmente, a qualidade em serviços turísticos tem recebido uma atenção cada vez maior por parte dos pesquisadores e empresários do setor, pois tem uma relação direta com a satisfação do turista em sua estadia na localidade.

\section{Qualidade em serviços turísticos}

O termo "qualidade" pode ser compreendido de diferentes formas no âmbito da gestão organizacional, por exemplo, para Slack et al. (1997, p. 552), a qualidade pode ser definida como "a consistente conformidade com as expectativas dos consumidores". Particularmente em serviços, a 
qualidade pode ser compreendida como o "grau em que as expectativas dos clientes são atendidas/excedidas por sua percepção do serviço prestado" (GIANESI; CORRÊA, 1994, p. 196). Essas definições são coerentes com as atividades do setor de turismo, que compreende 0 conjunto de organizações que prestam serviços turísticos.

A dificuldade de avaliação da qualidade em serviços impulsionou os autores da área a definir diferentes conjuntos de critérios que pudessem facilitar este processo (PARASURAMAN; ZEITHAML; BERRY, 1985 e 1988, GHOBADIAN; SPELLER; JONES, 1994; JOHNSTON, 1995). Os critérios de avaliação da qualidade em serviços propostos por Gianesi e Corrêa (1994) representam uma síntese dos critérios que podem ser encontrados na literatura e que continuam sendo válidos como parâmetros de análise de serviços turísticos. Esses critérios podem ser verificados no QUADRO 2, a seguir.

QUADRO 2 Os critérios de avaliação da qualidade em serviços

\begin{tabular}{c|l}
\hline Critério & \multicolumn{1}{c}{ Significado } \\
\hline \hline Tangíveis & $\begin{array}{l}\text { Referem-se a quaisquer evidências físicas do serviço, tais como aparência } \\
\text { dos funcionários, instalações de apoio e equipamentos utilizados no } \\
\text { processo. Engloba as dimensões de estética, limpeza e conforto. }\end{array}$ \\
\hline $\begin{array}{c}\text { Consistência } \\
\text { Competênci } \\
\text { a }\end{array}$ & $\begin{array}{l}\text { Conformidade com experiência anterior, ausência de variabilidade no } \\
\text { resultado. }\end{array}$ \\
\hline $\begin{array}{c}\text { Velocidade } \\
\text { de } \\
\text { serviço. }\end{array}$ & Rapidez e prontidão para atender o cliente. \\
\hline $\begin{array}{c}\text { Atendimento } \\
\text { /Atmondimento }\end{array}$ & $\begin{array}{l}\text { Refere-se ao quão agradável é a experiência que o cliente tem durante o } \\
\text { processo de prestação do serviço. Inclui a cortesia dos funcionários e a } \\
\text { atenção personalizada ao cliente. }\end{array}$ \\
\hline Flexibilidade & $\begin{array}{l}\text { Capacidade de mudar e adaptar o serviço para se ajustar às necessidades } \\
\text { dos clientes. }\end{array}$ \\
\hline $\begin{array}{c}\text { Credibilidade } \\
\text { ISegurança }\end{array}$ & $\begin{array}{l}\text { Baixa percepção de risco por parte do cliente e habilidade de transmitir } \\
\text { confiança. }\end{array}$ \\
\hline Acesso & Facilidade de entrar em contato ou acessar fisicamente o serviço. \\
\hline
\end{tabular}

Fonte: Adaptado de GIANESI e CORRÊA (1994).

É possível avaliar a qualidade dos Postos de Informações Turísticas por meio dos critérios apresentados no quadro 2, já que os PIT's são considerados prestadores de serviços de informação. A escolha desses critérios é justificável e coerente com outras pesquisas que se propuseram a analisar a qualidade de serviços turísticos (por exemplo: CARO; GARCÍA, 2008; CALLAN; KYNDT, 2001; O'NEILL et al., 2000).

Ao analisar um serviço turístico, é necessário que se leve em consideração um aspecto central para a avaliação da qualidade: as pessoas que prestam o serviço. Os serviços turísticos geralmente são intensivos em mão-de-obra, sendo que a motivação dos prestadores de serviços pode influenciar significativamente na qualidade do produto turístico, principalmente por meio dos critérios consistência, competência, 
velocidade de atendimento, atendimento/atmosfera, flexibilidade e credibilidade/segurança. Como as informações fornecidas pelos PIT's representam uma parte essencial do produto turístico, a responsabilidade dos funcionários dos PIT's torna-se ainda maior, pois as falhas ocorridas na prestação do serviço não permitirão correções sem que o turista perceba a ocorrência defeituosa e comprometedora da imagem do destino.

Além das pessoas, existem outros aspectos que podem influenciar na qualidade do serviço prestado pelos PIT's. Tais aspectos estão relacionados às próprias funções dos PIT's descritas anteriormente, como a estrutura física, o tipo de informação fornecida (verbal e escrita), dentre outros. Todos esses aspectos contribuíram para o desenvolvimento da metodologia de análise utilizada nesta pesquisa, apresentada na seção a seguir.

\section{Procedimentos metodológicos}

Considerando que os Postos de Informações Turísticas fazem parte do produto turístico, este artigo se propôs a analisar as condições dos PIT's do município de Florianópolis/SC para garantir a qualidade do atendimento aos turistas. Na revisão da literatura foi possível constatar que os aspectos que podem influenciar na qualidade percebida dos PIT's estão relacionados: (i) às pessoas que lidam com os turistas (prestadores de serviços); (ii) à infra-estrutura dos locais em que são prestadas as informações, desde o acesso ao estabelecimento até as condições da edificação e dos equipamentos de trabalho; (iii) ao material impresso disponibilizado aos turistas; e (iv) às informações verbais prestadas aos turistas.

Na área cinza da FIG. 3 é possível verificar os aspectos que podem influenciar na qualidade dos serviços dos PIT's. Esses aspectos foram selecionados como parâmetros de análise utilizados nesta pesquisa. A correspondência dos aspectos selecionados com os critérios genéricos de avaliação da qualidade em serviços, propostos por Gianesi e Corrêa (1994), é apresentada no QUADRO 3.

No período de realização da coleta de dados estavam funcionando quatro PIT's no município de Florianópolis, que representaram as principais fontes de dados primários. Sob o ponto de vista metodológico, a pesquisa caracterizou-se como um estudo de caso, de caráter qualitativo, exploratório e descritivo.

Os dados coletados foram tratados de forma agregada, de modo que os resultados da pesquisa fossem capazes de gerar sugestões de melhoria que pudessem ser aproveitadas em todos os PIT's do município, guiando as políticas públicas de informação ao turista. Desse modo, a principal unidade de análise da pesquisa foi caracterizada pelo conjunto total dos PIT's de Florianópolis. Para a operacionalização da pesquisa, cada um dos quatro PIT's representou uma subunidade de análise, dentro do conceito de "unidades de análise incorporadas" (YIN, 1994). Nesse sentido, a 
análise individual de cada um dos PIT's forneceu importantes insights para toda a estrutura de informações turísticas do município, retornando das subunidades para a unidade de análise maior.

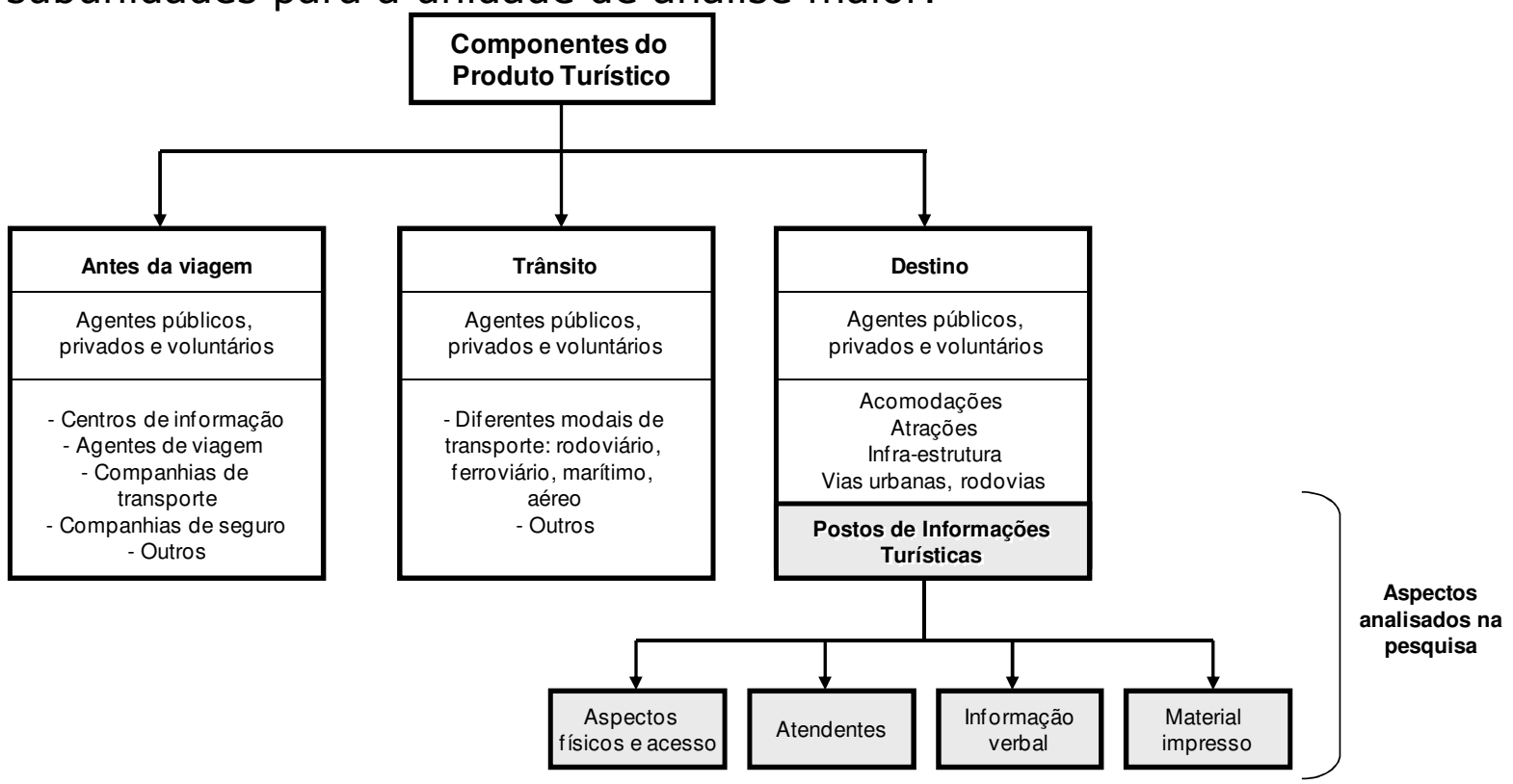

FIGURA 3 - Aspectos analisados nos Postos de Informações Turísticas

Fonte: Dados da pesquisa.

QUADRO 3 Critérios de avaliação da qualidade dos PIT's.

\begin{tabular}{|c|c|}
\hline $\begin{array}{c}\text { Aspectos } \\
\text { analisados }\end{array}$ & Critérios de avaliação da qualidade \\
\hline $\begin{array}{l}\text { Aspectos } \\
\text { físicos e de } \\
\text { acesso }\end{array}$ & $\begin{array}{l}\text { - Tangíveis: equipamentos, infra-estrutura física e tecnológica. } \\
\text { - Acesso: localização, sinalização, estacionamento, linhas telefônicas e } \\
\text { terminais de internet. }\end{array}$ \\
\hline Atendentes & $\begin{array}{l}\text { - Tangíveis: apresentação e aparência dos funcionários. } \\
\text { - Competência: formação, habilidade e conhecimento dos atendentes para } \\
\text { executar o serviço. } \\
\text { - Velocidade de atendimento: tempo gasto no processo de atendimento. } \\
\text { - Flexibilidade: mudança de atitude de acordo com a necessidade do cliente. } \\
\text { - Atendimento/Atmosfera: clareza na comunicação, receptividade, simpatia e } \\
\text { cordialidade dos funcionários com os turistas. }\end{array}$ \\
\hline $\begin{array}{l}\text { Informação } \\
\text { verbal }\end{array}$ & $\begin{array}{l}\text { - Consistência: uniformidade de procedimentos realizados durante o } \\
\text { atendimento. } \\
\text { - Credibilidade/Segurança: confiabilidade das informações repassadas pelos } \\
\text { atendentes. }\end{array}$ \\
\hline $\begin{array}{l}\text { Material } \\
\text { impresso }\end{array}$ & - Tangíveis: aspectos físicos e disponibilidade dos materiais de divulgação. \\
\hline
\end{tabular}

Fonte: Dados da pesquisa.

As técnicas de coleta de dados adotadas foram o questionário, a entrevista semi-estruturada e a observação passiva. Os questionários foram aplicados aos atendentes dos PIT's como uma forma de manter a objetividade na avaliação da qualidade dos serviços prestados, mas sem o interesse de tabular estatisticamente os dados, pois não havia uma amostra representativa para tal. A aplicação do questionário foi feita 
"face-a-face", de modo que era criado em paralelo um ambiente para entrevistas informais (não-estruturadas), o que enriquecia a coleta de dados junto aos atendentes. Durante a coleta de dados in loco (nos PIT's) eram utilizadas técnicas de observação passiva, orientadas por um checklist de avaliação, e o registro dos aspectos observados. Além disso, foi realizada uma entrevista semi-estruturada com o Diretor do Departamento de Turismo da Secretaria Municipal de Turismo (SETUR) de Florianópolis, responsável pelos PIT's, para verificar o direcionamento atual das políticas públicas de informação ao turista e, posteriormente, confrontá-lo com aquilo que foi constatado in loco.

\section{0 caso dos postos de informações turísticas do município de Florianópolis/SC}

Os Postos de Informações Turísticas (PIT's) de Florianópolis estão diretamente subordinados à Secretaria Municipal de Turismo (SETUR). Em consonância com seus objetivos de atuação, os principais serviços prestados pela Secretaria de Turismo de Florianópolis (SECRETARIA MUNICIPAL DE TURISMO - SETUR, 2008) são: desenvolver o turismo mediante o planejamento e o fomento da atividade; programar, organizar e executar eventos de natureza turística; e oferecer informações turísticas. Segundo a SETUR (2008), os PIT's são considerados um dos mais importantes canais de comunicação da Secretaria, prestando serviços públicos que são essenciais ao fomento da atividade turística.

A análise realizada nos PIT's foi baseada nos critérios sintetizados no QUADRO 3. Os resultados dessa análise são apresentados nas subseções a seguir.

\subsection{Aspectos físicos e de acesso}

Foi possível constatar que a localização dos PIT's era adequada, uma vez que eles estavam situados em regiões de fluxo intenso de turistas. No entanto, havia a necessidade de realização de algumas melhorias em relação à sinalização viária e à identificação nas portas de acesso. Além disso, a acessibilidade a deficientes físicos nos prédios era precária, tanto nas salas quanto nos banheiros. Ainda em relação ao acesso, convém mencionar as limitações do horário de atendimento, pois os PIT's não possuíam um horário padronizado para todos eles, o que gerava uma falta de credibilidade por parte do turista.

A estrutura de salas de trabalho foi considerada adequada na maioria dos PIT's analisados, exceto em um deles, que necessitava de um trabalho de readequação. O mobiliário encontrava-se em condições adequadas na maioria dos PIT's pesquisados, embora fosse necessária a aquisição de alguns móveis para armazenamento e arquivamento de materiais informativos. De uma forma geral, considerou-se que a estrutura física das salas, apesar de não possuir todos os itens 
recomendados na literatura, atendia à finalidade maior a que se propunha.

A limpeza e a manutenção dos banheiros dos PIT's localizados fora dos terminais de transporte de passageiros (aeroporto e rodoviária) apresentaram deficiências, pois não atenderam às condições mínimas prescritas nos itens avaliados no check-list da análise observacional. Como uma das funções secundárias dos PIT's é a disponibilização de banheiros para os turistas, pode-se considerar que as más condições dos banheiros influenciam indiretamente, mas de forma negativa, no processo de disseminação das informações turísticas.

Um dos principais pontos fracos que foram constatados na pesquisa de campo se refere à defasagem tecnológica dos PIT's, pois nem todos possuíam telefones, computadores, fax ou acesso à internet. A falta de acesso a mecanismos informatizados comprometia de forma contundente a qualidade da prestação de serviços informacionais, influenciando, por exemplo, na agilidade, na confiabilidade e na flexibilidade do atendimento. O simples acesso à internet já seria um grande instrumento de melhoria dos PIT's, uma vez que muitas informações poderiam ser consultadas online, com precisão e economia de custos de telefonia.

\subsection{Atendentes}

A apresentação física dos atendentes foi considerada adequada, embora a grande maioria não utilizasse nenhuma identificação (uniformes ou crachás). A SETUR disponibilizava crachás, no entanto, estes não eram utilizados. Por se tratar de um aspecto visível aos olhos do turista, a adoção de identificação poderia impactar positivamente em sua percepção de qualidade.

No que tange à formação e à competência dos atendentes, constatou-se um elevado número de estagiários, em sua maioria estudantes de ensino médio ou de graduação fora da área de Turismo. Grande parte dos atendentes não possuía experiência em turismo e não falava outros idiomas (além do português). Embora representassem a minoria, os estagiários do curso de Turismo demonstraram um interesse maior em aprimorar o trabalho, independentemente das dificuldades existentes (um estagiário trouxe um armário de casa, para guardar o material impresso, e o outro, por falta de acesso on-line, pesquisava periodicamente, em sua residência, informações para os turistas que buscavam entretenimento na cidade). Segundo a afirmação de um entrevistado, "o comprometimento de um atendente que estuda na área em que trabalha tende a ser maior do que o dos que possuem outros interesses".

$\mathrm{Na}$ solicitação de informações pormenorizadas sobre atrativos turísticos, os atendentes, de uma forma geral, eram ágeis na prestação do serviço, garantindo a rapidez no atendimento. Já para a solicitação de informações que dependiam de materiais impressos, a velocidade de atendimento variava de acordo com a disponibilidade desses materiais. 
Devido à ausência de mobiliário para arquivamento dos materiais informativos, constatou-se, de um modo geral, a lentidão na procura de materiais, mesmo quando estes estavam disponíveis. Assim, o quesito "velocidade no atendimento" não foi atingido eficazmente nessas situações.

Em se tratando do atendimento/atmosfera, a clareza na comunicação foi um item que deixou a desejar, pois se verificou a utilização excessiva de gírias locais, causando dificuldades na transmissão de informação para turistas de outras regiões do Brasil e, principalmente, para estrangeiros. De acordo com os dados coletados na SETUR, a ocorrência de tais fatos era provavelmente uma das conseqüências da ausência de um processo de capacitação dos atendentes.

A SETUR realizava pesquisas de feedback em relação aos serviços prestados nos PIT's. No entanto, percebeu-se a necessidade de um vínculo maior entre as equipes de trabalho, de forma a disseminar o conhecimento gerado entre os diferentes envolvidos nos PIT's, criando fluxos informacionais verticais (entre a direção e os atendentes) e fluxos informacionais horizontais (entre os atendentes dos diferentes PIT's).

\subsection{Informação verbal}

Embora não houvesse um padrão previamente definido para o fornecimento de informações verbais, o procedimento básico consistia na explicação sobre os serviços turísticos mais solicitados, acompanhada da entrega do material impresso referente àquela explicação. No entanto, quando um turista solicitava uma informação de um serviço turístico específico, a maioria dos atendentes demonstrava despreparo, indicando diferentes locais, mas sem a segurança de que aqueles locais realmente poderiam atender às necessidades solicitadas.

Para aumentar a credibilidade das informações verbais que eram transmitidas, os atendentes poderiam colocar os turistas em contato com as empresas e os operadores turísticos de que necessitavam. Porém, a deficiência nos equipamentos e na infra-estrutura de comunicação geralmente dificultava esta tarefa.

Durante as observações efetuadas nos PIT's, verificou-se que os turistas saíam aparentemente satisfeitos com o tipo de informação fornecida. Entretanto, para verificar a real percepção de confiabilidade da informação fornecida nos PIT's, ainda é necessário realizar uma pesquisa de satisfação diretamente com os usuários (turistas). Além disso, a outra dimensão básica da confiabilidade se refere ao conteúdo da informação, que complementa a análise, mas está fora do escopo deste trabalho.

\subsection{Material impresso}

A grande maioria dos materiais impressos disponibilizados era proveniente da iniciativa privada. Não foram encontrados materiais informativos dos principais destinos do Brasil ou de outros estados da Região Sul. Além disso, o mapa da cidade (centro e praias) não era 
disponibilizado em todos os PIT's nas versões em português, em inglês e em espanhol, apesar de ser o material mais solicitado.

Os temas mais procurados nos postos de informações eram: atrativos naturais, meios de hospedagem e serviços de alimentação. Sobre os meios de hospedagem e os serviços de alimentação havia informativos em quantidade suficiente, pois eram oferecidos por hotéis e restaurantes que, naturalmente, tinham a intenção de divulgar seus serviços. Entretanto, foi constatada uma escassez de informativos sobre os atrativos naturais, agravada pelo número reduzido de mapas turísticos da cidade, que também indicavam atrativos naturais em seu conteúdo.

Os atendentes reclamaram da falta de mapas da cidade e da região, no entanto, estes não repassavam esse tipo de informação para a SETUR. Além disso, não havia um canal de comunicação formal que indicasse, a partir da demanda nos PIT's, quais eram os informativos mais procurados pelos turistas. Assim, reforça-se a importância da presença de um agente responsável exclusivamente pela gestão dos PIT's, de forma a estreitar o relacionamento entre a direção e os postos.

Embora tenha sido verificada a ausência de materiais considerados importantes para os turistas, de uma forma geral havia uma imensa quantidade de folders nos PIT's. Porém, em sua maioria, eram informativos desnecessários, que dispersavam os objetivos dos PIT's e não traziam as informações mais procuradas pelos turistas. Esse excesso de informativos dificultava a organização física dos PIT's, causando transtornos no armazenamento e prolongando o tempo de procura dos materiais. Dessa forma, o objetivo de atingir a "rapidez no atendimento" era prejudicado por aquilo que poderia ser considerado como "lixo informacional".

\subsection{Sugestões de melhoria para os PIT's analisados}

Após analisar as condições dos PIT's para o atendimento ao turista em Florianópolis e confrontá-las com os objetivos da Secretaria Municipal de Turismo (SETUR), foi possível elaborar algumas sugestões de melhoria, conforme pode ser observado no quadro 4 apresentado a seguir.

Para cumprir as suas funções e se tornarem verdadeiros canais de comunicação da SETUR, os PIT's precisam aprimorar dois aspectos importantes:

1. Informações internas: o fluxo de informações entre os PIT's e destes com a direção precisa ser reestruturado, de forma que todos os locais envolvidos com a atividade de prestação de informações turísticas dentro da SETUR estejam aptos a fornecer qualquer tipo de informação.

2. Pesquisa de perfil e demanda turística: os PIT's municipais poderiam atuar como agentes de coleta de dados sobre o perfil dos visitantes e sobre a demanda turística. Esse tipo de informação é importante, inclusive, para a determinação das principais necessidades de atendimento nos PIT's. 


\section{QUADRO 4 Sugestões de melhoria}

\begin{tabular}{c|l}
\hline Aspectos & \multicolumn{1}{c}{ Sugestões de melhoria } \\
\hline \hline \multirow{4}{*}{ Aspectos físicos } & - Melhorar a sinalização viária e nas portas de entrada. \\
e de acesso & - Adquirir mobiliário para armazenamento de material informativo. \\
& - Melhorar a limpeza e a organização dos banheiros. \\
& - Adquirir equipamentos de informática, linhas e aparelhos telefônicos. \\
- Padronizar o horário de atendimento em todos os PIT's.
\end{tabular}

Fonte: Dados da pesquisa.

A adoção das sugestões apresentadas poderá contribuir para que os PIT's exerçam definitivamente o seu papel na implantação das políticas públicas de turismo e colaborem siginificativamente para a qualidade do produto turístico.

\section{Considerações finais}

A cidade de Florianópolis é considerada a capital do turismo no MERCOSUL, destacando-se no cenário nacional e na América do Sul como um dos locais em que a atividade turística mais cresce. Porém, para consolidar a cidade como um dos principais destinos turísticos do país, é necessário garantir a qualidade de todos os elementos do produto turístico. Nesse sentido, a avaliação dos Postos de Informações Turísticas representa um passo inicial em direção à melhoria da qualidade deste importante componente do produto turístico total.

A informação é um recurso estratégico que influencia diretamente nas decisões do usuário de turismo e, conseqüentemente, na qualidade percebida dos destinos. Levando em consideração que grande parte das pesquisas sobre esse tema tem o foco nas informações coletadas antes da viagem, este trabalho procurou contribuir para a análise dos meios de disseminação das informações que são coletadas durante a realização da viagem. Para isso, foram propostos alguns aspectos de avaliação da 
qualidade dos PIT's no que diz respeito à prestação de serviços de informação: aspectos físicos e de acesso, atendentes, informação verbal e material impresso. Esses aspectos foram utilizados para efetuar uma análise crítica dos PIT's do município de Florianópolis, o que forneceu a base para a proposição de algumas sugestões de melhoria.

Embora tenha sido feita uma análise preliminar, de caráter exploratório, foi possível identificar inadequações que dificultam o processo de disseminação das informações necessárias para a qualidade da permanência do turista na cidade. De uma forma geral, os PIT's do município de Florianópolis ainda têm um longo caminho a percorrer para se tornarem unidades de informação de excelência. No entanto, a estrutura de gestão da informação que já existe demonstra que o aprimoramento dos PIT's é viável, a começar pela implantação das sugestões apresentadas.

Pelo fato de os PIT's terem sido analisados apenas na perspectiva dos atendentes e dos pesquisadores, a validade das conclusões obtidas ainda é limitada e sinaliza a necessidade de continuidade da pesquisa por meio de um estudo de usuários da informação. O estudo de usuários poderia ajudar a definir as reais necessidades de informação por parte dos turistas, além de complementar a avaliação dos PIT's ao incluir as variáveis de satisfação dos clientes em relação aos serviços prestados.

Outro caminho para a continuidade deste trabalho está na análise do conteúdo da informação que é fornecida. Na pesquisa relatada neste artigo procurou-se analisar aspectos relacionados com o processo pelo qual a informação era transmitida e disseminada, mas sem levar em consideração aquilo que era realmente repassado para o usuário. Embora o conteúdo da informação seja diretamente influenciado pelo seu processo de disseminação, é importante expandir a análise das unidades de informação para a análise da informação propriamente dita.

De fato, o desenvolvimento do turismo em localidades que passam por um processo de expansão dessa atividade depende de políticas públicas que apóiem a manutenção do crescimento por meio da melhoria da qualidade de seus produtos turísticos. A gestão da informação é um processo fundamental para esse ideal, sendo que a melhoria dos Postos de Informações Turísticas representa uma parte essencial desse processo.

\section{Referências}

ACERENZA, M. A. Administração do turismo. 4. ed. São Paulo: EDUSC, 2002.

AUGUSTYN, M. M. The road to quality enhancement in tourism. International Journal of Contemporary Hospitality Management, v. 10, $\mathrm{n}$. 4, p. 145-158, 1998.

BENI, M. C. Análise estrutural do turismo. 8. ed. São Paulo: Senac, 2003.

BUHALIS, D. Strategic use of information technologies in the tourism industry. Tourism Management, v. 19, n. 5, p. 409-421, 1998. 
CALLAN, R. J.; KYNDT, G. Business travellers' perception of service quality: a prefatory study of two European city centre hotels. International Journal of Tourism Research, v. 3, n. 4, p. 313-323, 2001.

CARO, Laura Martínez; GARCÍA, Jose Antonio Martínez. Developing a multidimensional and hierarchical service quality model for the travel agency industry. Tourism Management, v. 29, n. 4, p. 706-720, 2008.

COOPER, C. et al. Turismo: princípios e prática. 2. ed. Porto Alegre: Bookman, 2001.

DE LUCCA FILHO, V. Estudo do fluxo de informações em centros de informações turísticas de Santa Catarina: programa portais do lazer. 134f. Dissertação (Mestrado em Ciência da Informação) - Universidade Federal de Santa Catarina, Florianópolis, 2005.

GHOBADIAN, A.; SPELLER, S.; JONES, M. Service quality: concepts and models. International Journal of Quality \& Reliability Management, v.11, n. 9, p. 43-66, 1994.

GIANESI, I. G. N.; CORRÊA, H. L. Administração estratégica de serviços: operações para a satisfação do cliente. São Paulo: Atlas, 1994.

HU, C. Diverse developments in travel tourism marketing: a thematic approach. International Journal of Contemporary Hospitality Management, v. 8, n. 7, p. 33-43, 1996.

JOHNSTON, R. The determinants of service quality: satisfiers and dissatisfiers. International Journal of Service Industry Management, v. 6, n. 5, p. 53-71, 1995.

LEHTO, X. Y.; KIM, D.; MORRISON, A. M. The effect of prior destination experience on online information search behaviour. Tourism and Hospitality Research, v. 6, n. 2, p. 160-178, 2006.

MIDDLETON, V. T. C. Marketing de turismo: teoria e prática. Rio de Janeiro: Campus, 2002.

MONTEJANO, J. M. Estrutura do mercado turístico. 2. ed. São Paulo: Roca, 2001.

NAISBITT, J. Paradoxo global. Rio de Janeiro: Campus, 1994.

NASCIMENTO, M. J.; SILVA, P. S. Informação: insumo básico para o desenvolvimento do setor de turismo em Santa Catarina. Perspectivas em Ciência da Informação, v. 9, n. 1, p. 48-69, jan./jun. 2004.

NISHIMURA, S.; WARYSZAK, R.; KING, B. The use and perceived usefulness of information sources among Japanese overseas tourists. Tourism and Hospitality Research, v. 6, n. 4, p. 284-295, 2006.

O'CONNOR, P. Distribuição da informação eletrônica em turismo e hotelaria. Porto Alegre: Bookman, 2001.

O'NEILL, M A. et al. Diving into service quality: the dive tour operator perspective. Managing Service Quality, v. 10, n. 3, p. 131-140, 2000. 
PARASURAMAN, A.; ZEITHAML, V. A.; BERRY, L. L. A conceptual model of service quality and its implications for future research. Journal of Marketing, v. 49, n. 4, p. 41-50, Fall 1985.

- SERVQUAL: A multiple-item scale for measuring consumer perceptions of service quality. Journal of Retailing, v. 64, n. 1, p. 12-40, Spring 1988.

POON, A. Tourism and information technologies. Annals of Tourism Research, v. 15, n. 5, p. 531-549, 1988.

RUSCHMANN, D. Marketing turístico: um enfoque promocional. 4. ed. Campinas: Papirus, 1999.

SEABRA, C. ; ABRANTES, J. L.; LAGES, L. F. The impact of using no media information sources on the future of mass media information sources: the mediating role of expectations fulfillment. Tourism Management, v. 28, n. 6, p. 1541-1554, 2007.

SECRETARIA MUNICIPAL DE TURISMO, CULTURA E ESPORTES (SETUR). Disponível em: <http://www.florianopolisturismo.sc.gov.br/secretaria/_html/relatorio.htm >. Acesso em: 01 ago. 2008.

SILVA, J. A. S. Pensando o planejamento face à intervenção do estado no turismo: a questão do sistema de informações. Turismo: visão e ação, v. 2, n. 5, p. 9-22, out.1999/mar. 2000.

SLACK, N. et al. Administração da produção. São Paulo: Atlas, 1997.

TEIXEIRA, E. L. Gestão da qualidade em destinos turísticos. Rio de Janeiro: Qualitymark, 1999.

WHEELER, M. Tourism marketing ethics: an introduction. International Marketing Review, v. 12, n. 4, p. 38-44, 1995.

YIN, R. Case study research: design and methods. 2.ed. Thousand Oaks: Sage Publications, 1994.

ZEITHAML, V. A.; PARASURAMAN, A.; BERRY, L. L. Problems and strategies in services marketing. Journal of Marketing, v. 49, n. 2, p. 3346, Spring 1985. 